\title{
Synchronic Account of Substitution among Educated Ohaozara Speakers of English
}

\author{
Okechukwu Okorie, Joekin Ekwueme, and Nkeiru Angela Ezeh
}

The synchronic sound changes which was an Abstract - Substitution is a natural experience among second accompaniment of structuralism is the focus of this study. language speakers because it occurs in a situation where the target There can be no linguistic change that does not affect the language presents segments that do not exist in the native language phonological processes in any natural language. Such of speakers. Native speakers, therefore, unavoidably try to processes include syllable structure processes, assimilation, are present in the foreign language but unavailable in their mother substitution, and dissimilation. The penultimate process is the tongue. It is against this linguistic pedigree that this study explored major concern of this study as it has assumed a nightmare the synchronic account of substitution among educated Ohaozara scenario to second language speakers. It, indeed, becomes a speakers of English using the Natural Phonology Hypotheses (NPH) "can't help" situation for second language speakers to use as its analytical tool. The study aimed to identify and account for what they have and substitute for what they do not have. In a the particular cases of phonological substitution as it affects predicament where the target language presents a phoneme thereafter, recommend workable and sustainable remedies that that is not available in the mother tongue, a second language would mitigate the problem. Data for the study were collected speaker is pushed to a tight corner and might resort to through the use of audio recorder and a reading comprehension substitute a similar segment present in their native language passage. One hundred (100) educated Ohaozara speakers of for the one absent. In a nutshell, substitution is a type of English, who were drawn at random, using the stratified random auditory based change involving the replacement of one

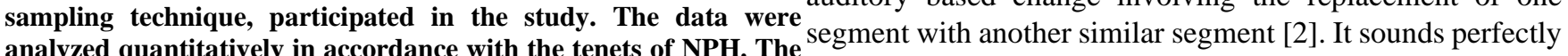
results showed that the speakers exhibited acts of phoneme plausible to say that half of the builders of the Tower of Babel substitution in most of their spoken discourses in English as came to Nigeria and settled after the project was halted by evidenced by both data. The study offered a good number of linguistic proliferation. The result was that virtually every recommendations and suggestions to mitigate the problem. community has a language that is either partially different and intelligible to others or totally different and unintelligible to

Index Terms - English as a Second Language, Ohaozara others, thereby, making her a hubbub of ethno-linguistic speakers, phonology, substitution, synchronic account.

\section{INTRODUCTION}

A paraphrased Newton's Law of Inertia might say that an object would remain stationary or inert until a greater force displaces it. This was the state of language before twentieth century when traditional grammarians held sway. Language as a system of communication remained rigid and inelastic, sternly averse to change or dynamism. Those early linguists permitted no form of fluidity in linguistic analysis. Prescriptivism was their watchword. To them, as it was in the beginning, so it should be and should ever remain world without end. They championed a linguistic analysis that should cut through the entire historical trajectory, otherwise called diachronicism. Any attempt to relax any linguistic strand was to them, an outrage on grammatical sanctity, a "corruption" [1] of the original which should be rejected. Written language had ascendancy over spoken language as the latter was lightly esteemed. There was a pervading sense that written language retained its purity while the spoken version was somewhat intractable and thus, deserved less emphasis. multiplicity. The latest figure of 513 languages and dialects was put forward by [3] citing [4]. The same source citing [5] had earlier put it between 394 and 400 languages. Another scholar put the figure between 400 and 500 [6]. However, the figures thinned out with each older research. For instance, it was 400 in [4], 394 in [7], 374 in [8], 250 in [9] and 150 in [10]. Each successive research yielded higher figures that indicated either that some remote linguistic communities abound that escaped the count of earlier ones or that new languages were still progressively evolving. So, it goes without saying that Nigeria is chronically a multilingual nation. A position vehemently supported in [11, 3, and 12]. Then the synopsis of the multilingual reality in Nigeria was aptly furnished by [12] citing [11].

The truth of the matter is that English language arrived as an uninvited guest to many native Nigeria languages and dialects. This contact turned most Nigerians into bilinguals, compelled as it were, to learn the English language in addition to their mother tongue. Some people say it was an imposition, others say it was a voluntary adoption of a necessary evil, supplanting relic of colonialism. At any rate, English language has come to stay in spite of whatever opinion people hold about it. On arrival, English language declared it assets which included some phonemes that are alien to native languages. However, most speakers of English as a Second

Published on June 25, 2021.

Okechukwu Okorie, Federal School of Statistics, Nigeria.

Joekin Ekwueme, University of Nigeria, Nigeria.

(corresponding e-mail: joekinekwuemeyahoo.com)

Nkeiru Angela Ezeh, University of Nigeria, Nigeria. 
Language found substitution handy as a potent antidote to the linguistic lacuna. A practice that involves "the replacement of one segment with another similar segment within the same phonological environment [2]. However, in spite of the huge justification for substitution, Onuigbo submits that we should, therefore, note the distinctive characteristics of each consonant and pay special attention to the three consonants which do not occur in Nigerian languages. "These consonants are $/ \theta /$ ठ/and $/ 3 /$ and experience show that they are usually substituted with other consonants which occur in the learner's mother tongue. This kind of substitution should be avoided" [13]. It is against this backdrop, therefore, that we attempted to investigate the synchronic account of substitution among educated Ohaozara speakers of English.

\section{A. Statement of the Problem}

This study does not set out to solve the general problem of substitution because it will always be there in spite of countless studies and recommendations on it. This study makes a solemn discovery - an entire civilization had been left out by previous researchers. Substitution as it affects the whole community of Ohaozara educated speakers, vis-à-vis their peculiar ethno-linguistic environment, had not been brought into perspective by any of the previous studies. This, the researchers see as a scholastic gap that needs to be filled.

\section{B. Research Objectives}

The general objective of the study is to identify and account for the particular cases of phonological substitution as it affects Ohaozara educated speakers of the English language and thereafter, recommend workable and sustainable remedies that would mitigate the problem. The other specific objectives of the study are:

i. to identify the prominent sources of phonological substitution among educated Ohaozara speakers;

ii. to describe instances of phonological substitution in utterances by Ohaozara educated speakers;

iii. to ascertain if phonological substitution by Ohaozara educated speakers can hamper their communication with the outside world;

iv. to establish whether or not substitution of some phonemes by Ohaozara educated speakers are as a result of dialectal interference.

\section{Scope of the Study}

The study only attempts to explore issue of replacement of segments that are available in the English language but absent in the mother tongue with other similar segments by educated Ohaozara speakers within a particular point in time. It intends to identify and explain such instances of substitution that are observable among second language users from Ohaozara who are moderately literate and living within a specific period, with a view to proffering phonological solution for teaching and learning purposes.

\section{LITERATURE REVIEW}

Substitution has received a barrage of investigative shots from all angles by researchers. By late twentieth century, it had become an object of curious interest following the contact made by the English language with the native languages in Nigeria particularly. The frictions that greeted the contact situation jolted researchers into studies that produced a lot of relevant literatures.

Blazing the trail in the analysis of segmental features, [3] submitted the following conclusions from his findings: that the standard Nigerian English is fraught with consonant substitution for the voiced and voiceless dental fricatives /ð $\theta /$ in this manner: /ð $/ \rightarrow / \mathrm{t} / ; /$ / $/ \rightarrow / \mathrm{d} / ; / \theta / \rightarrow / \mathrm{t} /$; that in a particular ethno linguistic setting within the country, there is an interchangeable membership substitution between the voiceless bilabial plosive /p/ and the voiceless labio-dental fricative /f/ thus: /p/↔/f/: that the discreet sound segments (vowels and consonants) were diminished or simplified callously by second language speakers for instance, diphthongs were reduced to monophthongs among other things.

The findings, as instructive as they were, have spanned over three decades and therefore due for appraisal [3]. Some of the conclusions have been queried and found untenable at present [3]. For instance, it was discovered that Ibibio language contains some of the diphthongs in the target language like, /ai, a $\boldsymbol{U}, \mathrm{Ii} / a /$. Ezeagu dialect in Enugu State also contains /ei,ai,בi/. So, his conclusion on monophthongization of English diphthongs may no longer be absolute. In fact, when the relevant unit or structure of both languages is the same, linguistic interference can result in correct production called positive transfer.

Four years after, explores the circumstances of language transfer among second language speakers and users and its socio-cultural and linguistic relationships [14]. He examined the intricacies of language transfer at various levels of linguistic analysis: phonology, syntax, and semantics. Phonology was adjudged the most troublesome, because speaking is the most psychologically demanding of all the skills of language acquisition. In conclusion, he opined that in the circumstance where some phonemes are present in the mother tongue of speakers but absent in the target language, the last resort becomes substitution. When substitution is employed to make up for a lack, it is according to him, seen as a negative transfer.

Shortly after, in what seems like another version of Hunjo's Periodization, experimentally categorized the Nigeria English into three, namely: Contact English (CE) Victorian English (VE) and School English (SE). He further subdivided the contact English into Nigeria Pidgin (NP) and Broken English (BE). The study found among other things that the dominant features of Standard Spoken Nigerian English (SSNE) include the substitution of Nigerian language's vowels and consonants for English ones and the replacement of stress by tone. It also identifies the composition of the standard Nigerian English to include contact English, Victorian English and of course, the most prominent of all, the School English and finally elucidates the concept of Nativisation [4].

[15] presents explanation on the likely pronunciation errors evident to Tiv learners of English phonotactics. The researchers adopted a descriptive method and optimality theoretical framework to note the possible constraints the Tiv learners of English as L2 encountered. Tiv speakers of the English realize phonotactics of English words differently. They violate the phonotactic rules of the language in realizing consonant clusters, assimilation, and vowel harmony. The 
study observes that the Tiv learners experienced difficulties in realising English syllabic pattern with consonant clusters; they find it difficult pronouncing it without the insertion of a vowel sound, hence, transferring this feature from their language to the L2. Tiv also has onset restriction for syllables i.e., most syllables have onset. In other words, no vowel can begin a syllable except at word initial stage.

In addition, [16] undertook to investigate the "Yoruba/English Bilingual's phonological Transfer." The study as cited in Josiah (2014) observes that "inadequate phonemic differentiation and the substitution of a syllable prosody for the isochronicity of stress in standard English are features of practically all of varieties I, II and III, with instances thinning out as we go from variety I". it further reveals that vowel reduction widely reported in Nigerian English is peculiar to Yoruba speakers as well as other speakers of the Nigerian English.

Similarly, two compilations of consonant sounds - one for Received Pronunciations and the other for Nigerian English - with a view to discussing how consonants from both lists are used interchangeably by speakers with careless abandon, were presented by [17]. The alveolar plosives $/ \mathrm{t} /$ and $/ \mathrm{d} /$ are spoken instead of the dental fricatives $/ \theta /$ and $/ \delta /$, the palatoalveolar fricative $/ \int /$ for another palate-alveolar fricative $/ 3 /$, the bilabial plosive /p/ for a labio-dental fricative /f/, another labio-dental fricative / $/ \mathrm{v}$ for a bilabial plosive /b/ among others. This phenomenon lends credence to the reality of domestication of the English language in Nigeria as he posits, “... the domestication of English in Nigeria certainly has social linguistic values" (p. 36). The standard British English now reflects Nigeria elements as it has assumed and assimilated characteristics of the Nigerian socio-cultural and sociolinguistic environment. These findings buttress the position of the present enquiry. Nevertheless, research is an open-ended matter, hence, the present researcher intends to dig deeper into the subject so as to update the earlier findings for the purpose of standardization.

Within the same year, [18] investigates expansively the concept of domestication of English language in Nigeria. At the end of which he declares: "we have adapted it for home use and made it applicable to our numerous conveniences, experiences, nuances and sensibilities" (13). He makes a long list of the phonological developments that characterize the Nigerian English to include: insertion of vowels in syllabic consonants e.g., cotton $/ \mathrm{katin} /$, the insertion of epenthetic vowels in some consonant clusters e.g. spring/sipiriy/, reduced vowel system e.g., beans /binz/, the substitution of alveolar fricatives for inter-dental fricatives, reduced intonation system, absence of consonant clusters in words, like strength, non-differentiation in some respects of length where native varieties would do so, absence of glottalization in some contexts which is obligatory in native English environments and the voicing of voiceless consonant endings. It is the substitution related item that is most relevant to the present study.

[19] explored aspects of connected speech process (CSPs), the phenomenon that accounts for sound modifications in speech. The aim was to establish features that characterize standard Nigerian English connected speech. The paper adopted Natural Phonology (NP) as its theoretical standpoint.
This theory provides explanations for substitutions, variations in the speech of second language speakers. Data were sourced from 360 educated Nigerian English speakers across the country. These data were transcribed in accordance with the tenets of CSPs and NP and then analyzed quantitatively by allotting marks to instances of occurrences and converting such to percentages. Three categories of CSPs were identified: dominant, minor, and idiosyncratic processes. The study affirms only the dominant CSPs, typical of Nigerian English speakers were acceptable as standard Nigerian speakers' English.

The likes of [12] assembles and analyze the various models on standard Nigeria English phonemes which they sourced from linguists and examined them against those of the Standard English. The study tenaciously undertakes to investigate the crises of modeling and harmonizing standard Nigeria English phonemes at the end of which it glimpses the emergence of a national standard. The aim is to establish that even with the combined influences of speakers' mother tongue and their sociolinguistic backgrounds, national intelligibility and social acceptability are not hampered significantly in the hybridized variants spoken among different linguistic backgrounds in Nigeria. The study used a corpus-based approach and sampled respondents from nineteen (19) linguistic groups in Nigeria and the results show that rather than impede national intelligibility, these adapted or nativized variants instead provide some linguistic harmony and foster a desirable national cohesion and identity among the diverse sociolinguistic groups.

Summarily, the works reviewed therein are related to the present study in that both studies (current and previous) investigated phonological substitutions among Nigerian speakers of English. However, while previous studies examined substitution among speakers of other Nigerian indigenous languages; the current study investigates the synchronic account of substitution among educated Ohaozara speakers of English thereby filling this gap.

\section{THEORETICAL FRAMEWORK}

The Study adopted David Stampe's Natural Phonology Theory to address the theoretical issues in this study. Specifically, this study adopted Natural Language Hypothesis propounded by the same exponent as its analytic tool.

According to [20], Natural Phonology Hypothesis (NPH) characterizes production and perception of speech in terms of a set of universal phonetically motivated phonological processes. Before their first words, infants identify some processes as inapplicable in their language, which narrows their perceptual universe to its phonemic system and enables them to hear the intention rather than the actuation of speech. They then gradually inhibit the inapplicable processes to achieve mature pronunciation. If some inhibitions are not fully mastered, the child's speech seems to have a sound change, or perhaps a variable pronunciation, or a speech deficit. Processes that remain active govern allophony, variation, automatic alternations, one's native "accent", and one's "foreign" accent in second-language learning. Inactive processes may (re-)emerge to cope with stresses like injury or fatigue. 
More so, it was maintained that the theory of natural phonology Hypothesis takes the discrepancies to be due to the operation of natural processes, categorical mental substitutions, each of which responds in real time to an innate limitation of the human faculty for fluent speech perception and production. It takes non-discrepancies to be due to inhibitions of those processes - inhibitions that are mastered in acquiring the pronunciation of a particular language. Since all languages and individuals have the same processes, the phonology of a speaker of a particular language consists entirely of these inhibitions. The processes are universal [21].

Again, it was argued that Structural phonology - whether at Geneva, Copenhagen, Prague, Yale, London, Harvard, or MIT - focused mainly on describing the language-particular discrepancies between ideal and actual speech, with statements classing mutually predictable sounds into phonemes, or conversely, stating the realizations of phonemes in different contexts. Even at MIT, where the discrepancies are stated in terms of phonetic "natural classes", they were still widely regarded merely as conventions of the language. Some of the discrepancies were said to be "natural" or "phonetically motivated" because they arose as gradual mechanical changes because the origin of the mechanical changes has been obfuscated by subsequent changes. And it is true that phonetic explanations of alternations like loaf/loaves or keep/kept belong to history children assume these are loafs and keeped, and must learn the "accepted" forms - because the alternations live on only as conventions [21]. But they are conventions of grammar, not phonology: they are not discrepancies between intended versus actual speech at all, but between distinct intentions.

The Theory also holds that "phonological processes are innate and universal - not in the sense of "Universal Grammar", but rather in the sense that they are natural responses to the phonetic difficulties encountered in speaking" [21]. They are universal because the human vocal and perceptual apparatus is universal - not because they are somehow part of the human brain. They may be discovered by the child in the process of using his vocal tract - during vocalization, crying, or babbling - and still we call them "innate", since their origins and motivations are innate. Rules must be learned by observing other speakers. The innate elements in phonology are the phonetic forces (processes, constraints, or preferences) that press toward optimization and motivate substitutions. Optimization can take place along two dimensions: (a) paradigmatic: optimizing individual segments, particularly at prosodic peaks and edges; and (b) syntagmatic: optimizing sequences of segments over prosodic divisions. The learned elements in phonology are the speaker's acquired inhibitions that let him achieve (a) the phoneme inventory and (b) the phonetic realizations that he perceives as the communicative and cultural and stylistic requirements of family and community. English speakers could say /sorınt1/ for serenity, but convention demands

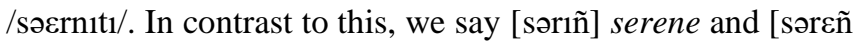
1t1] serenity with nasalized vowels, because we have not been required to learn to exercise enough timing control to say $*$ [sərin] and *[sərenit1].

\section{Methodology}

The study adopts the descriptive survey design. The instruments used to extract the data for the study include a tape/audio recorder and a comprehension passage of an English text. These instruments are considered most suitable in this research because the research itself focuses on spoken discourse (phonological substitution). The whole Ohaozara educated speakers of the English language in Ebonyi State, Southeast, Nigeria roughly estimated at five thousand (5000) constitute the population of this study. The researcher, however, deemed it necessary to classify all Ohaozara intellectual elite into three: The University graduates, three thousand (3000); Polytechnic graduates, one thousand (1000) and College of Education graduates, four hundred (400). This set of people classified thereof are the population of the study.

The researcher used the stratified random sampling technique to select a representative sample of one hundred (100) respondents, which included 50 men and 50 women who are university and polytechnic graduates. Graduates of Colleges of Education were not selected in this study to enable the researcher to manage effectively the data generated. More explicitly, ten (10) respondents were selected from each of the ten (10) towns that make up Ohaozara Local Government Area. The subjects for the study were all natives of Ohaozara with an average tertiary education literacy acquired within and outside Ebonyi State.

The data for the study were collected via the use of tape/audio recorder, and the use of a reading comprehension passage. In other words, the researcher would tape-record some sample of words the respondents produced and also record their rendering of the reading comprehension passage. The transcripts of the recorded utterances are made thereafter for the purpose of analysis. Summarily, a corpus approach was employed, and education formed the fundamental criterion for analyzing the data collected from respondents. The corpus used for the analysis included ten simple words pronounced by respondents and a short paragraph of fifty words read by respondents into an audio tape.

The study adopts qualitative and quantitative methods of data analysis. The researchers would first make a transcript of the recorded data and scan for elements or features of phonological substitutions in the respondents' utterances. Again, the data generated from 'reading' would be listened to thoroughly since it was tape-recorded, then features of phonological substitutions, if any, would be identified. The linguistic features of phonological substitutions identified would be analyzed in accordance with the tenets of Natural Phonology Hypotheses (NPH).

\section{RESUlTS}

TABLE I: RESPONDENTS VARIANTS IN THE REALIZATION OF THE EXPRESSION: “APPROACH HER”. CONTROL'S REALIZATION: /OPRӘYT $\int$ Hə/

\begin{tabular}{|c|c|c|c|}
\hline Pronunciation & Code & Frequency & $\%$ \\
\hline /əprəut \. hə & әH1 & 7 & 7 \\
\hline aprot $\int$ ha: & $\mathrm{AH} 2$ & 59 & 59 \\
\hline a:pr t $\int$ ha: & AH3 & 9 & 9 \\
\hline a:profa: & AH4 & 11 & 11 \\
\hline \multirow[t]{2}{*}{ a:prout ha: } & AH5 & 14 & 14 \\
\hline & 5 & 100 & 100 \\
\hline
\end{tabular}


TABLE II: RESPONDENTS VARIANTS IN THE REALIZATION OF THE EXPRESSION: TABLE IX: RESPONDENTS'VARIANTS IN THE REALIZATION OF THE WORD: "COULD BE REJECTED”. CONTROLS REALIZATION: /KYD BI RID3EKTID/

\begin{tabular}{|c|c|c|c|}
\hline Pronunciation & Code & Frequency & $\%$ \\
\hline kvd b1 $\mathrm{r}_{3} \mathrm{~d}_{3} \mathrm{ekt1d}$ & KR1 & 9 & 9 \\
\hline kvd b1 rid $_{3}$ eted & KR2 & 37 & 37 \\
\hline kvb b1 rid reted & KR3 & 34 & 34 \\
\hline ku: b1 rid $_{3}$ eted & KR4 & 7 & 7 \\
\hline ku:ld b1 rid $_{3}$ ekted & KR5 & 8 & 8 \\
\hline kvd b1 $\mathrm{rid}_{3} \mathrm{kted}$ & KR6 & 5 & 5 \\
\hline & 6 & 100 & 100 \\
\hline
\end{tabular}

TABLE III: RESPONDENTS' VARIANTS IN THE REALIZATION OF THE EXPRESSION: “HE WILL TOUCH” CONTROL's REALIZATION: /HI WIL T T]/

\begin{tabular}{cccc}
\hline Pronunciation & Code & Frequency & $\%$ \\
\hline h1 w1l t 4 t & HT1 & 9 & 9 \\
h1 wo to:t & HT2 & 36 & 36 \\
h1 w1: to:t & HT3 & 23 & 23 \\
h1 w1 to:t & HT4 & 8 & 8 \\
h1 w1:1 to:t & HT5 & 18 & 18 \\
1 w1:1 to:t & HT6 & 6 & 6 \\
& 6 & 100 & 100 \\
\hline
\end{tabular}

TABLE IV: RESPONDENTS' VARIANTS IN THE REALIZATION OF THE EXPRESSION: "THE FIRST MAN" CONTROL'S REALIZATION: /ĐӘ F3:ST MÆN/

\begin{tabular}{cccc}
\hline Pronunciation & Code & Frequency & $\%$ \\
\hline de f3:st. mæn & DM1 & 12 & 12 \\
d1 f :st ma:n & DM2 & 21 & 21 \\
de fest ma:n & DM3 & 59 & 59 \\
di f3:st men & DM4 & 8 & 8 \\
di fest ma:n & DM5 & 12 & 12 \\
& 5 & 100 & 100 \\
\hline
\end{tabular}

TABLE V: RESPONDENTS' VARIANTS IN THE REALIZATION OF THE EXPRESSION: "THIS DATA". CONTROL'S REALIZATION: /ĐIS DEITЭ/.

\begin{tabular}{cccc}
\multicolumn{4}{c}{ CONTROL'S REALIZATION: /ĐIS DEITӘ/. } \\
\hline Pronunciation & Code & Frequency & $\%$ \\
\hline d1s deitə & DD1 & 2 & 2 \\
dis deitə & DD2 & 3 & 3 \\
dis da:ta: & DD3 & 66 & 66 \\
dis deta: & DD4 & 18 & 18 \\
ð1s deta & DD5 & 9 & 9 \\
di deta & DD6 & 2 & 2 \\
& 6 & 100 & 100 \\
\hline
\end{tabular}

TABLE VI: RESPONDENTS' VARIANTS IN THE REALIZATION OF THE EXPRESSION: "SING BASS" "CONTROL'S REALIZATION: /SID BEIS/

\begin{tabular}{cccc} 
Pronunciation & Code & Frequency & $\%$ \\
\hline sin beis & SB1 & 6 & 6 \\
sing bes & SB2 & 18 & 18 \\
sin ba:s & SB3 & 10 & 10 \\
sing ba:s & SB4 & 66 & 66 \\
- & - & - &. \\
- & - & - &. \\
& 4 & 100 & 100 \\
\hline
\end{tabular}

TABLE VII: RESPONDENTS' VARIANTS IN THE REALIZATION OF THE WORD: "PAINTING"CONTROL'S REALIZATION/PEINTID/

\begin{tabular}{cccc}
\hline Pronunciation & Code & Frequency & $\%$ \\
\hline peintın & PT1 & 17 & 17 \\
pentın & PT2 & 33 & 33 \\
peintin & PT3 & 12 & 12 \\
pentin & PT4 & 31 & 31 \\
pe:ntın & PT5 & 7 & 7 \\
& 5 & 100 & 100 \\
\hline
\end{tabular}

TABLE VIII: RESPONDENTS' VARIANTS IN THE REALIZATION OF THE WORD: "FEBRUARY" CONTROL'S REALIZATION: /FEBRYəRI/

\begin{tabular}{cccc} 
WORD: "FEBRUARY" CONTROL'S REALIZATION: /FEBRYəRI/ \\
\hline Pronunciation & Code & Frequency & $\%$ \\
\hline febrvor1 & FB1 & 7 & 7 \\
febuer1 & FB2 & 11 & 11 \\
febr1 & FB3 & 30 & 30 \\
febuar1 & FB4 & 36 & 36 \\
febrar1 & FB5 & 16 & 16 \\
& 5 & 100 & 100 \\
\hline
\end{tabular}

"THROAT". CONTROL'S REALIZATION: /@RӘYT/

\begin{tabular}{ccccc}
\hline & Pronunciation & Code & Frequency & $\%$ \\
\hline & Hrovt & T1 & 16 & 16 \\
& Orout & T2 & 28 & 28 \\
trout & T3 & 53 & 53 \\
& trot & T4 & 2 & 2 \\
& tr :t & T5 & 1 & 1 \\
& & 5 & 100 & 100 \\
\hline
\end{tabular}

TABLE X: RESPONDENTS' VARIANTS IN THE REALIZATION OF THE WORD: "NORTH-EAST" CONTROL'S REALIZATION: /N : $\Theta-I: S T /$

\begin{tabular}{ccccc}
\hline & Pronunciation & Code & Frequency & $\%$ \\
\hline o & $\mathrm{n}: \theta-1: \mathrm{st}$ & $\mathrm{NE} 1$ & 29 & 29 \\
0 & $\mathrm{n}: \mathrm{t}-1: \mathrm{st}$ & $\mathrm{NE2}$ & 58 & 58 \\
? & $\mathrm{n}: \mathrm{t}-1 \mathrm{st}$ & $\mathrm{NE3}$ & 8 & 8 \\
& $\mathrm{not}-\mathrm{h} 1: \mathrm{st}$ & $\mathrm{NE} 4$ & 4 & 4 \\
? & $\mathrm{n}: \theta-1 \mathrm{st}$ & $\mathrm{NE5}$ & 1 & 1 \\
& & 5 & 100 & 100 \\
\hline
\end{tabular}

TABLE XI: RESPONDENTS' VARIANTS IN THE REALIZATION OF THE WORD:

\begin{tabular}{cccc}
\multicolumn{4}{c}{ "PUSH" CONTROL's REALIZATION: /PY J/ } \\
\hline Pronunciation & Code & Frequency & $\%$ \\
\hline pv $\int$ & P1 & 8 & 8 \\
pu: $\int$ & P2 & 77 & 77 \\
pu:t & P3 & 4 & 4 \\
pu:s & P4 & 3 & 3 \\
puj & P5 & 7 & 7 \\
pvs & P6 & 1 & 1 \\
& 6 & 100 & 100 \\
\hline
\end{tabular}

TABLE XII: RESPONDENTS' VARIANTS IN THE REALIZATION OF THE WORD: "VISION" CONTROL'S REALIZATION: /VI3N/

\begin{tabular}{|c|c|c|c|}
\hline Pronunciation & Code & Frequency & $\%$ \\
\hline $\mathrm{V1}_{3} \mathrm{n}$ & V1 & 10 & 10 \\
\hline v1: $\int_{0}$ & $\mathrm{~V} 2$ & 60 & 60 \\
\hline v1 $\int \mathrm{n}$ & V3 & 8 & 8 \\
\hline v1 $\int_{0 n}$ & V4 & 17 & 17 \\
\hline \multirow[t]{2}{*}{$\mathrm{V}_{3} \mathrm{On}$} & V6 & 5 & 5 \\
\hline & 5 & 100 & 100 \\
\hline
\end{tabular}

\section{DISCUSSIONS}

On Table I, the expression presented was "Approach her". Respondents pronounced it in a continuous speech. Among the respondents" variants in the realization of "approach her" AH2 /a:protaa:/ obviously was the most significant item. A whooping 59 respondents subscribed to it. The Standard British English Variant, /əprovt/ hə/ was realized by only 7 respondents. The reason is not far-fetched. Among educated Ohaozara speakers, the diphthong /av/ is not generally realized just like their counter parts in other part of Nigeria. It was averred that most Nigerians substitute /o/ for /əv/ [15]. Agreeing to this finding, it was stated that "this fact is also attested in many other studies on Nigerian English [22). Little wonder why as many as (84\%) of our respondents replaced /o/ for /ov/ in "approach". A careful study of the respondents' variants on this table shows that (79\%) of the investigated speakers elided the initial sound in "her".

It is noteworthy that Ohaozara people love travelling. Some families would actually live in other parts of Nigeria for a better part of their lives and only retire home at old age. This explains why a little percentage of our respondents were Ohaozara natives but born and bred among other ethnic nationalities. The articulations of this class of educated Ohaozara speakers were heavily influenced by the environments of their exposure. That is why we have /apr o t $\mathrm{a}: /$ and /a:profa:/ among the variants. Those who spent most 
of their lives in the north among the Hausa, Fulani and Nupes realized the former while those who sojourned in the west among Yorubas and Ijaws articulated the latter. This is because the Hausa, Fulani and Nupes have / i:/ and / 1/ but not /o/ phonemically, thus, /aprovt $f /$ becomes /a:prot $\int /$. The Yorubas and Ijaws naturally would substitute $/ \mathrm{J} /$ for $/ \mathrm{t} / \mathrm{J}$ which is not available in their mother tongue, hence my "Yorubanized" and "Ijawish" brothers rendered /oprəvt $\int /$ as /a:pro $/$. This manner of substitution lends credence to proposition that mother tongue interference could be the man behind the mask of some pronunciation problems among (L2) second language learners.

The expression "could be rejected" on Table II yielded six variants but the ones with striking significant features are KR2 and KR3 terms /kvd b1 $\mathrm{r}_{3} d_{3}$ eted/ and /kvb b1 r1d $\mathrm{d}_{3}$ ekted/ respectively. This is owing to the fact that Regressive Voicing Assimilation (RVA) has obviously taken place. The voiced alveolar plosive /d/ is elided and substituted for another voiced bilabial plosive $/ \mathrm{b} /$ in an anticipatory manner. Naturally, the alveolar plosive /d/ is voiced but it may be devoiced when it occurs at the final position of a word. Having lost its voice in this circumstance, it becomes conventional for it to give way for the following voiced segment $/ \mathrm{b} /$ in a connected speech. It is characteristics of voiceless segment to "copy" or assimilate some features of voiced segments in voiced environment. This proximity influence could result in total deletion or "deadening" of the voiceless segment by the overwhelming voiced sound. The phenomenon of consonant devoicing in final position is not strange in this case because it has been established to be a remarkable hallmark of the Nigerian English by earlier studies which include. Educated Ohaozara speakers are also bitten by the bug being a microcosm of the larger Nigerian speech community. The inferable conclusion here is that not only mother-tongue influence but proximity of sounds in certain phonological environments could account for some cases of perceived substitution of segments.

It is ridiculous but a bitter reality that $91 \%$ of respondents pronounced the past tense marker "ed" of the word "reject" as /ed/ instead of / $1 \mathrm{~d} /$ in the Standard British English (SBE). This is due to the fact that most educated Ohaozara speakers tend to pronounce words according to their spelling symbols. An error that makes our pronunciation sound "unEnglish. In conclusion following the spelling symbols of words accounts substantially for some cases of substitution of phonemes.

On Table III, the expressions "He will touch" and "The first man" were displayed. For the first expression, thirty-six respondents representing $36 \%$ pronounced it as /h1wv tot $/$. Only nine respondents realized the Received Pronunciation (RP) variant exemplified by the Control. Eight (8) realized it as $/ \mathrm{h} 1 \mathrm{w} 1 \mathrm{l}$ tot $\mathrm{f} /$ while six articulated the form $/ 1 \mathrm{w}: 1 \mathrm{tot} / 23 \%$ of the respondent articulated the form /h1 w1: tot $\int /$ Eighteen (18) of the respondent pronounced the expression as $/ \mathrm{h}_{1} \mathrm{wl}$ : tot $/$ /Ohaozara is currently inhabited by a heterogeneous people who have imbibed different cultures and accent hence the multi-farious realizations. Some respondents of Ohaozara origin had been greatly influenced linguistically by their environments of exposure which confirm some findings of earlier studies and provide relevant clues to most linguistic studies in Nigeria. The variant with the highest index, /h1 wv tot $/$ could be explained thus: both the high front vowel $/ 1 /$ as well as the lateral /1/ were elided by syncopation while the back vowel /u/ becomes consolidated as the available substitute. We offer the following explanation to the variant forms noticed in this item. It has been observed that many Nigerians fail to realize the syllabic lateral in words like little, middle, etc. [23]. This is described as an instance of a cluster break rule in which an epenthetic vowel is inserted to substitute for the $/ 1 /$. Thus "little" /11tl/ becomes [litu], people /p1:pl/ becomes ['pıpu], and so on. The same source also explains a similar phonological process known as Lvocalization which describes a situation whereby speakers change $/ 1 /$ into a vocalic sound (usually the vowel $/ v /$ ). He explains that this is because of the auditory similarity between /l/ and /u/ as could be seen with the word "will" which we are considering here. He then draws the conclusion that this may also be noticed with RP speakers which means it is a phonetic factor not just peculiar to Nigerian English speakers. The second most significant variant is coded HT3 which is slightly different from the RP variant in that the vowel [1] was neutralized. The next variant form [h1 w1l tot $/$ was noticed more with the home-bred Ohaozara speakers. The [wu] variant was noticed to occur in the realizations of those who lived among the Idomas, Tivs, Igalas, Yorubas and Hausas. But majority articulated the long [1:] variant. Generally, the variants cut across the various linguistic groups. One conclusive remark to make here is that /i/ and /w/ are brief versions of [i] and $[\mathrm{u}]$ and they can be used to substitute for each other in any environment that occasions it [24].

The expression "The first man" and "this data" jointly introduce a voiced interdental fricative /ð/ and feature on Table IV and $\mathrm{V}$, respectively. It is therefore convenient to combine their discussions. The segment is not known or present in Ohaozara mother tongue and according to [13] since this consonant does not exist in Nigerian languages, Nigerian learners of English usually experience some problem in pronouncing it. This problem results in such wrong pronunciations as "day" for "they" and "den" for "then". To avoid these faulty pronunciations therefore, learners should follow the articulatory procedure described above. The spelling symbol for $/ ð /$ is also "th". Apart from the problem of pronouncing $/ \theta /$ and / $\delta /$ correctly, there is an additional problem of knowing when to pronounce $/ \theta /$ and when to pronounce / $/$ since both consonants have the same "th" spelling. There is no established rule to guide the learners, but you may have noticed that some people usually pronounce "th" as $/ \mathrm{t} /$ in specific situations and pronounce the same "th" as /d/ in other situations. In such situations where such people pronounce "th" as $/ \mathrm{t} /$, the correct pronunciation is $/ \theta /$. In other situations where they pronounce "th" as $/ \mathrm{d} /$, the correct pronunciation is / $\mathrm{d}$.

This explains why evidently, most of the respondents as shown by the table did not articulate / $\mathrm{\partial} /$ but rather substituted it for /d/ in realizing "The first man" and "This data". The explanation is not far-fetched. Obviously, majority of the correspondents representing $89 \%$ articulated $/ \mathrm{d} /$ in the place of / ð/. In other words, they substituted the voiced alveolar plosive /d/ for the voiced dental fricative /ð/. Also, on Table $\mathrm{V}$, it is seen that the voiceless alveolar plosive /t/ was pronounced in place of the voiceless dental fricative $/ \theta /$. This substantiate the conclusions of earlier investigation on the 
matter, notable among them was the reciprocal membership substitution [3].

Tables IV and V present data that shows that an absolute majority of the respondents in the experimental group were unavoidably constrained to realize the voiced dental fricative / $\mathrm{d} /$ as the voice alveolar plosive /d/ not excluding the educated Ohaozara speaker who lived and worked in other parts of the country. Language users tend, however, unconsciously to leave no vacuum in their language. Where such was seemed, it is promptly filled up with what is available. In Asia, Korean language does not have the sound /v/, in its place, they articulate /b/. The same phonological situation exists in Hausa English [24], following the path of $/ ð /$ and $/ \theta /$. This beggars the question: Is it a coincidence or a design that these languages substitute the same phonemes for the absent ones in similar phonological environments? The answer is not farfetched. Two major explanations effectively address it. First, of course, is the issue of mother tongue interference where the phoneme that is not available in the speaker's mother tongue in replaced with the one present in the target language similar to it. The second explanation is connected with articulatory issues. There is the phonetic factor where if the articulatory organs fail to realize the labia dental fricative $/ \mathrm{v} /$, then the lips move towards the closest available organ in the anterior region, since both are labial sounds, to realize a bilabial plosive. This is the most plausible reason why most natural languages that do not have the labiodental fricative /v/ and /f/ invariably appropriate the bilabial plosive /b/ and /p/ respectively in their place. This explanation perfectly addresses the incident among Hausa speakers.

Similarly, the case of $/ \delta /$ and $/ \theta /$ can also be described as a natural precursor of substitution among second language speakers. Generally, the dental fricative $/ \delta /$ and $/ \theta /$ are believed to be "marked", that is, they are distinctive and unique phenomena not applicable to most languages [25]. It is believed that the substations of $/ \mathrm{t} /$ and $/ \mathrm{d} /$ or $/ \mathrm{s} /$ and /z/ for $/ \theta /$ and $/ \delta /$ respectively are common to non-native speakers' varieties, and for this reason, do not significantly impede intelligibility since contextual clues are available to aid intelligibility in non-native and native speakers' interaction. In the same vein, it is observed that the case of substitution of $/ \mathrm{d} /$ for $/ \mathrm{d} / / \mathrm{t} /$ for $/ \theta /$ as well as $/ \mathrm{z} /$ and $/ \mathrm{s} /$ for $/ \mathrm{d} /$ and $/ \theta /$ respectively combine issues of mother tongue interference and some phonetic facts. The Mother Tongue (MT) interference perspective is that these sounds are not available in the local language of those that speak to them, so the natural resort is to replace them with the closest or similar phoneme present in the speakers first language. The second explanation bothers on a phonetic reality. Both $/ \mathrm{\delta} /$ and $/ \theta /$ and their substitutes /d/ and /t/ are all [+anterior] sounds and are articulated as apico-dental segments, therefore when the tip of the tongue fails to hit its articulatory target, it readily rests at the next place of articulation closest to that target as a result of the articulatory constraints caused by the speaker's speech organs. This analysis so far presented, adequately explain why many educated Ohaozara speakers and non-native speakers realize $/ ð /$ as $/ \mathrm{d} /$ and $/ \theta /$ as $/ \mathrm{t} /$. Next is the concept of reciprocal membership substitution involving $/ \mathrm{p} / \leftrightarrow / \mathrm{f} /$ as stated in [3], the conclusion according to Josiah [12] is that all these cases of substitution apart from just being explained from the perspective of mother tongue interference, owe their source of influence from certain phonetic factors, especially that of the articulatory organs that produce these sounds.

It is noteworthy at this juncture, that the acrolectal speakers of Nigeria English identify and pronounce these segments underlyingly while their speech symbols are varied. This development according to [26] suggests that there is urgent need for fashioning out an endonormative model of spoken English in Nigeria since the Received Pronunciation form does not seem to provide a suitable model to Nigerian English speakers and learners.

What happens when the velar nasal $/ \mathrm{y} /$ occurs before the voiced plosive /g/ is the major preoccupation shown on Table VI. Respondents' performance is as anticipated. Majority of the respondents $(66 \%)$ realized the variant (sing ba:s) instead of (sing beis). Only 10\% could realize the standard British English model articulated by the control. Obviously, many people (94\%) were unable to pronounce the diphthong /e1/ in either the word "bass" (Table VI) or "painting" (Table VII). Instead /e/ was substituted for /e1/ in each case. This realization is corroborated by [27], among others, and the explanation is that the English diphthong does not have equivalents in some native languages in Nigeria but not all because it occurs in Hausa and Ezeagu language. This is no doubt, a case of mother tongue interference. For the expression "sing bass" /sin beis/ earlier mentioned, we found the substitution of $/ \mathrm{y} /$ for $/ \mathrm{n} /$ to be phonetically motivated rather than being occasioned by mother tongue interference. In Standard British English, the final segment of the first word $/ \mathrm{g} /$ is silent but majority of our respondent $(84 \%)$ pronounced it because silencing segment is not common in many Nigerian mother tongues. Again, Nigeria speakers of the English language tend to pronounce words according to the spelling symbols to ensure that no letter is left out; [13] advised against such practice because there could be silent segment in a cluster.

Moreover, since the two sounds $/ \mathrm{y}, \mathrm{g} /$ are velar sounds, it does appear that once the velum is deployed, it goes through the stretch. In actual fact, what majority of educated Ohaozara speakers pronounced was $/ \mathrm{n} /$ and not $/ \mathrm{y} /$ because the latter is alien to them and does not occur in their native language.

The word "February" posed a great difficulty to Ohaozara speakers because it contains a strange phenomenon, a "cluster". This explains why many of the respondents could not realize the second syllable. Clusters are not known in Ohaozara native language, hence, Ohaozara speakers did not hesitate to disband the cluster by inserting epenthetic vowel into it the same way diphthong are pronounced as segments. No wonder that majority of the respondents realized it as [febuar1] and [febuer1/ instead of /februor1]. Ohaozara indigenous language does not tolerate clusters but rather favours the alternate occurrence of consonantal and vocalic sounds. Clusters are simplified with intervening vowels inserted into them. Triphthongs are not pronounced at all because they do not occur in any mother tongue in Nigeria.

Majority of the respondents realized the word 'push' as /pu: $\int /$ instead of /pv $\int /$ on Table XII, obviously because the differentiation of the vocalic length between the two segments $/ v /$ and $/ \mathrm{u}$ :/ is often ignored. Although the phoneme is present in Ohaozara native language, it is always replaced with the longer sister to accord it its vocalic prominence, 
moreover, its spelling symbol looks like /u/. However, this is a short vowel which may be described as a back vowel even though the tongue part used for its articulation in nearer the centre then the back of the tongue. The lips are rounded while the jaw is in a closed position. Even in Ohaozara mother tongue, the spelling symbol is still a " $u$ " with a dot under it /ụ/. That explains why it is overshadowed by the /u:/ in the pronunciation of greater number of respondents.

Last but not the least, Table XII presents another nightmare of a phoneme to many educated people of Ohaozara. Little wonder that $(85 \%)$ of respondents articulated the sound as $/ \mathrm{J} /$. This is made unavoidable by the fact that its spelling symbol is often represented as "sion" as in "erosion", "fusion", "confusion", and so on, rhyming remarkably with its counterpart in "mission", "digression", "confession" to mention but a few. It is by careful study and constant practice that one can distinguish between words with $/ \mathrm{J} /$ and $/ 3 /$ sounds without interchanging them.

Worthy of note still on this table is the total disrespect for the syllabic consonants by educated Ohaozara speakers of English. This is in a bid not to omit the vowel which of course is the most prominent part of the syllable. So, any syllable that lacks a vowel will be provided with one as seen on the variants produced by $82 \%$ our respondents. However, in some syllables, a consonant can function as the nucleus of the syllable especially if the syllable has no vowel. Special consonants perform this function in English, and they are referred to as "syllabic consonants". The common syllabic consonants in English are (1) and (n). These two sounds function basically as consonants of English but if any of the two consonants occurs in a syllable and is therefore said to be syllabic.

Experience shows that learners of English pronunciation tend to insert a vowel before a syllabic consonant in order to simplify the pronunciation. Some learners may even drop a syllabic (1) and replace it with a vowel. We must, therefore, resist any urge to insert a vowel before a syllabic consonant or replace a syllabic consonant with a vowel as these errors will make our pronunciation sound "unEnglish".

\section{SUMMARY AND CONCLUSION}

Educated Ohaozara speakers of English largely do not realize the diphthong /ov/ but instead substitute /o/ for it. Secondly, some returnee educated Ohaozara people who spent a better of lives in the Western Region of Nigeria were accustomed to eliding the sound $/ \mathrm{h} /$ whenever it occurs at the initial position of words in their connected speech. Similarly, an insignificant number who lived in Niger Delta region removed $/ \mathrm{t} /$ / and pronounced $/ \mathrm{J} /$ instead, as was spoken by the people they lived with. It was also found that some educated Ohaozara speakers would readily devoice the voiced plosive /d/ if it occurs at the end of a word and substitute it for the following voiced segment. This is generally called Regressive Voicing Assimilation (RVA). These kinds of substitution are direct results of phonological environmental factors like proximity of the sounds involved, not necessarily Mother Tongue Interference.

Another remarkable finding was that speakers of English from Ohaozara do not tolerate consonant clusters. They would rather simplify it by adding intervening vowels into it.
This is owing to the fact that consonant clusters do not exist in their native language. Vocalic sounds occur in alternate positions with consonantal sounds and should end words Substitution is one of the phonological issues emanating from contract situation between languages as part of their blending processes. The practice of substituting the voiced interdental fricative $/ \delta /$ with the voiced alveolar plosive $/ \mathrm{d} /$ was also discovered. This is necessitated by the fact that since the former is absent in the mother tongue of Ohaozara speakers, they are unavoidably constrained to replace it with a similar segment present in their native tongue. The same goes for another voiceless dental fricative $/ \theta /$ which majority of respondents replaced with the voiceless alveolar fricative $/ \mathrm{t} /$. It is a totally strange segment to Ohaozara speakers who found its substitute more convenient and handier. As earlier stated, it is a natural tendency for educated Ohaozara speakers, when faced with the predicament of pronouncing a strange sound, to replace it with another segment that shares a high degree of phonetic similarity with them.

Another interesting linguistic issue found in this study was that a tiny percentage of Ohaozara educated speakers who were born and bred in the Northern region of Nigeria replaced the two labiodentals fricatives $/ \mathrm{v} /$ and /f/ with bilabial plosives $/ \mathrm{b} /$ and $/ \mathrm{p} /$ respectively. They picked up this habit from their environment of exposure where the fricatives do not exist in the local language. It was also found that silent segments were pronounced by majority of the respondents. For instance, the voiced velar plosive /g/ in "sing" was supposed to be silent but educated Ohaozara speakers like their counterparts in Nigeria as a whole would pronounce words after the letters of their spelling. They do not like to leave any letter unpronounced because in their native language, no written alphabet is omitted in pronunciation. Another important discovery was that most diphthongs were monothongized by Ohaozara speakers. The two diphthongs that featured on the experiment were reduced to single phonemes. For instance, /ov/ was realized as /o/ while /e1/ was pronounced as /e/ respectively by most respondents.

Conclusively, the standards of performance in English by Nigerians used to be higher than they are today; and indeed, those standards have been steadily declining. This judgment is no doubt made impressionistically by most people, who judge from the quality of the English language that they hear and read. As we shall see presently, the problems thrown up by the learning of spoken English are not of the same order as those posed by the learning of written English. In both cases, we are indeed concerned with intelligibility and conformity. And it may well be true that on the whole, Nigerian users of English attain better intelligibility and conformity with standard English world-wide in writing than speaking.

\section{RECOMMENDATIONS}

1. Speakers or users of a second language should have a change of attitude towards substitution and see it as a surmountable enemy of communication.

2. Individual should embark upon speech enhancement exercises such as pronunciation drills, enunciation and elocution practices, public speaking stress and intonation exercises and so on to improve their spoken English. 
3. There should be advocacy groups to sensitize the speaking community that speaking the standard variant does not mean sounding bookish or Europeanized.

4. Education authorities should ensure that only welltrained and practicing phoneticians are recruited to handle phonics in schools and colleges.

5. Government should train and re-train phoneticians locally and internationally who will in turn teach children how to articulate those difficult sounds and reduce phonetic apathy among students.

\section{SUGgestions FOR FURTHER STUdies}

Researches should be carried out on the following areas:

1. Synchronic account of de-frictioning of labio-dental fricative /f/ in Onitsha MT.

2. Articulation of diphthongs as vocalic segments in the spoken English of educated Ohaozara speakers of English.

3. Synchronic account of cluster simplification among educated Ohaozara speakers of English.

\section{REFERENCES}

[1] A. Johns, "Movement and language with complex morphology,"University of Maryland Working Papers in Linguistics, pp. 1-14, 2008

[2] A. Kirkpatrick, World Englishes: Implications for International Communication and English Language Teaching. Cambridge: Cambridge University Press, 2007.

[3] D. Eka, "Phonological study of standard Nigerian English", PhD Dissertation, Ahmadu Bellow University (ABU), Zaria. 1985.

[4] A. Bamgbose, "Models of communication in multilingual States, "West African Journal of Modern Languages, vol. 3, pp. 60-65, 1975.

[5] B. Elugbe, "National Language and National Development," in Multilingualism, Minority Languages and Language Policy in Nigeria, E.N. Emenanjo (Ed.). Agbor: Central Books, 1990.

[6] A. A Gittal, "How many are Nigerian languages?" in Nigerian Languages for National Development and Unity, O. Arohunmolase (Ed.). Ibadan: Lolyem Communications, 1998.

[7] J. S. Coleman, Nigeria: Background to Nationalism, Berkeley: University of California Press, 1958.

[8] K. Hansford, J. Bendor-Samuel and R. Standford, An Index of Nigerian Languages. Accra: Summer Institute of Linguistics, 1976.

[9] O. Otite, Ethnic Pluralism and Ethnicity in Nigeria, with Comparative NOTES, Ibadan: Shaneson, 1990.

[10] B. W. Tiffen, "The Intelligibility of Nigerian English," Ph.D. Dissertation, University of London, 1974.

[11] E.N. Emenanjo, How many Nigerian Languages are there? Issues on the Definition and Identification of Language. in Topical Issues in Sociolinguistics: The Nigerian Perspective. O. Essien \& M. Okon eds., Port Harcourt: Emhai Printing and Publishing Co, pp. 73-92, 2003.

[12] U. E. Josiah, "A Synchronic account of substitution in Nigerian English," Journal of the English Scholars Association of Nigeria (JESAN), Vol. 19, No. 1, July, 2017.

[13] S. Onuigbo, Oral English for schools and colleges (Revised Edition). Onitsha: Africana First Publishers Limited, 1997.

[14] B. B. Kachru, "World Englishes: agony and ecstasy," Journal of Aesthetic Education, vol. 30 (2), pp. 133-155, 1996.

[15] I. M. Udofot, "A tonal analysis of standard Nigerian English.," Journal of the Nigerian English Studies Association, vol. 3(1), pp. 58-68, 2007.
[16] A. Banjo, "Towards a definition of standard Nigerian spoken English," Actes du $8^{e}$ Congress de la Société Linguistique de L'Afrique Occidental, pp. 24-28, 1971.

[17] A. Adetugbo, "Problems of Standardization and Nigerian English Phonology," in Nigerian English: Influences and Characteristics, A.B.K. Dadziev \& S. Awonusi eds., Lagos: Concept Publications, 2004.

[18] E. Adegbija, "The Domestication of English in Nigeria," The Domestication of English in Nigeria: A Fetschrift in Honour of Abiodun Adetugbo, S. Awonusi \& E.A. Babalola (eds), Lagos: University of Lagos Press, 2004).

[19] R. M. Oladipupo, Aspect of Connected Speech Processes in Nigeria English, SAGE, pp. 1-6, 2014. Retrieved on the $17^{\text {th }}$ July, 2020 from www.sgo.sagepub.com.

[20] P. Donegan and D. Stampe, "Hypotheses of natural phonology," Pozan Studies in Contemporary Linguistics, vol. 45(1), pp. 1-31, (2009).

[21] Donegan and D. Stampe, "The Study of Natural Phonology," in D. A. Dinnsen (ed.), Approaches to Phonological Theory. Bloomington: Indiana University Press, 1979.

[22] M. M. Jibril, Phonological variation in Nigerian spoken English. Unpublished Ph.D. Dissertation, University of Lancaster. 1982.

[23] V. O. Awonusi, "Some Characteristics of Nigerian English phonology," in A.B.K. Dadziev \& S. Awonusi (eds.). Nigerian English: Influences and Characteristics, pp. 203-225. Lagos: Concept Publications.

[24] A. Teasdale (n.d.), "On the differential substitution of English /ब/: a phonetic Approach," Retrieved on the $18^{\text {th }}$ July, 2018.

[25] D. Crystal, A dictionary of linguistics and phonetics, 4th ed. Great Britain: Blackwell, 1997.

[26] U. E. Josiah, Multilingualism and Linguistic Hybridity: An Experiment with Educated Nigerian Spoken English," in Review of Arts and Humanities. U.S.A: American Research Institute for Policy Development, vol. 3(2). pp. 157-184, 2014. Retrieved 3/6/2016 from http://rah.net.com/vol.3.

[27] D. Jowitt, "Patterns of Nigerian English intonations," English Worldwide, 21, 63-80, 2000.

Okechukwu Okorie holds Bachelor and Master of Arts Degrees in English and Literary Studies, Faculty of Arts, University of Nigeria, Nsukka. $\mathrm{He}$ is a PhD candidate in the Department of English and Literary Studeis, University of Nigeria, Nsukka. He is a lecturer at the School of General Studies, (English the at Federal School of Statistics, Manchok, Kaduna State, Nigeria. His research interest lies in phonetics and phonology.

Joekin Ekwueme holds a Bachelor of Arts Degree in English/Education (B.A.Ed.), University of Jos; Master of Arts Degree in English (M.A.), University of Nigeria, Nsukka. He is currently pursuing his Doctor of Philosophy (Ph.D.) in the Department of English and Literary Studies, University of Nigeria, Nsukka. He had worked as a teacher and lecturer of English and Literature in secondary and adult Education Centers in some states of the federation. He has published articles in both International and Local journals. His research interest includes Phonology, Textlinguistics, Applied English Linguistics, Semiotics, Stylistics and Pragmatics. Mr. Ekwueme is a member of Teachers Registration Council of Nigeria and English Scholar's Association of Nigeria among others.

Nkeiru Angela Ezeh obtained her Bachelor of Arts Degree in English and Literary Studies from the University of Nigeria, Nsukka. She got her Master of Arts Degree in English and Literary Studies from Abia State University, Uturu. Currently, she is a PhD candidate at the Department of English and Literary Studies, University of Nigeria, Nsukka. She is a teacher and researcher in language and English linguistics. Her research interest is in phonology, discourse studies, pragmatics, and stylistics. She has equally published some articles in reputable journals. 